\title{
El diagnóstico de Georgio Colli sobre la "crisis de la modernidad"
}

\section{Introducción}

De acuerdo con Eugenio Trias, Colli es un pensador que ha dado a su obra un caracter "embozado y emboscado". Con ello quiere decir que para encontrar las lesis centrales que articulan al conjunto de su obra, es necesario previamente una labor de rescate y reelaboración de las mismas de entre una impresionante - y no menos importante - tarea editorial. Le obra de Colli ofroce, en consecuencia, la dificultad de encontrarse disperse a lo largo de toda su magnifica empresa sistematizadora y divulgadora, tanto del pensamiento griego preclásico como de algunos autores centrales de la filosoffa del siglo XXX, entre los que ocupan un primerfsimo lugar Schopenhauer y Niezzsche.

En efecto, para Trías, la noción sistematizadora de la obra de Colli se encuentra, ante todo, en la interpretación que ofrece de la naturaleza del Logos o, dicho de otra manera, la idea de racionalidad manejada por los autores presocráticos. De acuerdo con tal propuesta de interpretación, el Logos, antes que ser un instrumento técnico diseñado para conquistar el poder de la Polis - al y como de hecho fue comprendido por los sofistas-, es una forma profunda y milenaria de sabidura. Se trata, para Colli, de una sabidurfa originaria que nace del enfrentamiento o lucha del Logos con el fondo oscuro, primordial y violento de la realidad. Por elto le corresponde a la naturaleza del Logos un carácter polémico y agonal. También por ello, éste adquiere esta identidad tan característica en y desde su relación con el mito.

Según Trías, Colli sostiene que el mito es el espacio que proporciona un sustrato material al Logos. La sabiduría en que consiste el Logos estriba, por lo tanto. en ese enfrentamiento de la racionalidad con el misterio para arrancarle su sentido y significado. La sustilución de un Logos originario, agonal y dialectico por un espurio, es decir, contaminado por una concepción instrumental, habria marcado irreversiblemente el desarrollo de la historia cultural de Occidente. En las propias palabras de Trlas: 
"Es esta decantación técnico-política del Logos lo que detruye y desmantela el concepto sapiencial, presofistico del Logos, ese concepto que brota espontáneamente del mito de Dionisio, del carácter jónico y bifronte de esa divinidad, a la vez violencia originaria y apertura de un espacio de juego lógico de carácter polérnico y desuructivo"'.

En consecuencia, ésta sería una influencia negativa que ayudaría a explicar algunos rasgos de la crisis cultural de la actualidad. Concretamente, en el pensamiento de Colli existe la profunda convicción de que nuestra forma de pensar, esto es, nuestra racionalidad última, es heredera o deudora - según se vea, si bien muy a su pesar- de la influencia cultural helenistica. Claro que se trata de una influencia que primero ha sido ocultada y desconocida para ser luego contaminada y deformada.

En esta perspectiva, la crisis de la modernidad que hoy dla padecemos es el resultado de una suerte de desorden racional que es, precisamente, el resultado del desarrollo y puesta en práctica de los postulados del <<proyecto de la modernidad >. Tales postulados son, dicho de manera muy esquemática, un conjunto de principios excesivamente oplimistas sobre la capacidad de la razón humana para alcanzar las verdades o certezas profundas del mundo y del hombre. Son, por tanto, principios optimistas y acríticos, como la experiencia historica mostrada hasta la saciedad, que particularmente entrañan profundos peligros a la hora de guiar la conducta práctica de los hombres y los pueblos.

En efecto, la ciega confianza en la capacidad humana por alcanzar la verdad concebida en términos únicos e incontrovertidos suele devenir, por lo general, en un racionalismo dogmático e ideológicemente totalitario. Ello suele implicar, con suma frecuencia, que desde esa concepción de razón universal se pretende justificar la imposición de una forma de vida y de comprensión hegemónica, que no tiene reparos en 《sacrificar〉> a los seres humanos en un altar abstracto que puede ser denominado como: el Partido, la Nación, el Progreso, la Iglesia, las Leyes de la Historia, etc.

Por lo demás, cabe destacar que Colli es uno de los contados y, por tanto, <<raros〉> filosofos del presente que enjuicia sin miramientos, con justeza y con verdadera y necesaria dureza, los impresionantes y graves excesos de una época como la nuestra caracterizada por ser tan ilusa, desordenada, autocomplaciente y ciega. En realidad, no podía esperarse menos de un pensador que fue, como ya señalábamos, un genuino conocedor, seguidor y, también, crítico de la obra de Nietzsche.

¿Cuáles serían, en suma, los problemas vitales y radicales de nuestra presente modernidad según Colli? A mi juicio serían básicamente dos, a saber: (1) El dominio absoluto del Estado en la cultura. Se trata, en otras palabras, del control de la cultura por parte de la política y, también, el sometimiento de la cultura a los 
intereses de la polficica. Tal control, por ejemplo, se expresa claramente en la administración buroctática del pensamiento creativo y de la educación, por medio de instrumentos o instituciones tan sofisticadas y complejas como la misma universidad. (2) La subordinación o capitulación de la filosoffa frente a la ciencia, al punto de haberse convertido la primera en mera y simple servidora de la segunda.

\section{Sobre la "crista" del pensamiento actual o le crisis de le modernided}

La crítica de Colli al mundo conternportineo arranca de una crifica a la organización de la culura en dicho mundo. Ello por la obvia razón de que la cultura y sus frutos son la manifestacion mis tangible y objetiva de la vitalidad del hombre y de su modo y calidad de civilización.

Para Colli, la decadencia de la cultura es la expresión de, entre otros factores, una inadecuada relación del hombre con su entorno. En efecto, la relación del hombre moderno con su entomo niturit y su propio cuerpo debe obedecer a un "equilibrio natural" entre los estimulos externos del mundo y de las actividades esponténeas de los individuos ${ }^{2}$. Sin embargo, en nuestra epoca moderna - posthistórica le podremos tambien nlamer à se atiende a la justificada propuesta de Calasso- dicho equilibrio se ha pertido. Los hombres de hoy son seres dominados por el mero estimulo y sin capacided de apelar a sus fuerzas internas y a su espontaneidad. Por ello, Colli sostiene que:

"El desarrollo de la máquina ha multiplicado los estŕmulos y roducido la actividad espontánea y plena del hombre. El hombre espera que el mundo exterior venga a él, y cuanto menor deba ser su aportación (apretar el botón - de un mundo digital) tanto más feliz. Planteamiento milagrero: uno de los aspectos de nuestra barbarie"?

No se puede, cieramente, alcanzar o construir una culura vital, creativa, si el ideal de esa misma cultura es la pereza, como nos advierte Colli, e igualmente la sustitución -añadiŕa, por mi parte, de la mano de Calasso. Quizá, el mejor ejemplo de esta equívoca y peligrosa relación entre el hombre y su entorno sea la pretensión desmedida de la modernided por suprimir o, más bien, falsear la distancia y los límites naturales que emanan de las realidades fisicas del espacio y del tiempo, apoyándose en el poder de la teenica —por lo demás hija legitíma de la razón espuria, instrumental. Puede sostenerse, en consecuencia, que la tecnica es el principal instrumento para reprimir la espontaneidad en todas sus formas y con toda su riqueza.

Pero la modernidad no sólo combate la espontaneidad del hombre de culura, sino que también destruye aquellas condiciones o factores imprescindibles para crear una comunidad cultural viva y creativa. El estado, el modemo Leviatán, controla por entero la esfera de la cultura haciendo que sus intereses y valores se vuelvan hegemónicos. Para Colli, de hecho, el hombre de cultura en el mundo 
modemo es un hombre condenado al aislamiento, a le soleded, al abandono y, en los casos extremos, a la incomprensión, el ostracismo e, incluso, a la locura o al suicidio. Como dice el propio Colli:

"En los ultimos dos siglos no han faltado ciertamente los grandes individuos de cultura Su destino ha sido trágico. Por un lado carecían de una base segura, es decir, de una sociedad cultural que les educase y apoyara: como máximo eran autodidectas y aislados, que llegaron con esfuerzos terribles a resultados que hubieran podido ser simples puntos de partida Por otro lado, no pudieron nunca reunir sus resultados, crear una base para el futuro, dor una verdadera consistencia a lo que hablan vivido, salir de la soledad, resumiendo, expresarse de una forma acabada y alejarse de una vida desesperada, dominada por la necesidad material. Soledad, locura, suicidio, miseria, indiferencia, estos han sido sus destinos"'.

El cuadro que nos pinta Colli es desgarrador y doloroso. Sin embargo, el mismo autor nos da la respuesta, quizá más eficaz y, en cierto sentido, esperanzadora, que los individuos concretos y dotados de fortaleza interior comúnmente han manifestado frente al poder subyugador de ese mecanismo de control y dominación que es el Estado. Se trata de la grandeza de esplritu o da carfeter que el hombre de cultura puede ejercer si la posee o conquista. La grandeza de espiritu no es, por supuesto, ni renuncia, ni abdicación o resignación. Es, mis bien, una suerte de resistencia activa-pasiva que reconduce al individuo hacia su interior y le permite encontrar dentro de sf un espacio para la sobrevivencia de su propia riqueza y su propia identidad. En rzalidad, la grandeza es una virtud - más que activa o pasiva - contemplativa. Es la actitud de quien logra mantener la ecuanimidad e, incluso, alcanza a mantenerse indiferente frente a la buena o mala suerte.

La grandeza es, por tanto, un mecanismo eficaz para lograr sortear o sustraer a la propia condieión humana del torrente del conflicto y de la violencia siempre presente y constitutiva de los dinamismos de la vidas.

Por otra parte, la grandeza se manifiesta no sólo a través de la actiud existencial de quien excepcionalmente la posee, sino que también se revela en las diferentes esferes de la expresión humana, es decir, la filosofía, el arte, la ciencia, la religión, etc. Por supuesio que no cualquier expresión humana alcanza la condición de grandeza. En realidad, ni siquiera aquellas producciones humanas marcedes por la excelencia de su realización son forzosamente portadoras de grandeza. Para ello, para evidenciar o al menos reflejar la grandeza, el objeto o producto de la acción humana debe sustraerse, ante todo, de la cultura subordinada al poder del Estado y, además, revelar esa fuerza originaria del fondo primario, esencial y auténticamente verdadero de la realidad ${ }^{6}$. Dicho con otras palabras, para Colli, un producto humano digno de ser considerado tocado por la grandeza no es aquél que a pesar de su excelencia tiende hacia la acción o llegue a inspirar o potenciar un comporamiento organizado, sino, por el contrario, es aquella expresión (poética, política, estéti- 
ca, etc.) que posce la facultad de traducir o comunicar más que representar una experiencia interior.

Como fácilmente se comprendera, el ser humano poseedor de un esplritu de grandeza es una excepción a la noma. En cambio, son legión los espifitus dominados por la influencia de la cultura espuria de la modernidad. Ahora bien, qué es lo que esta cultura deformada y sometida por el poder del Estado refleja como su condición. Para Colli, los rasgos de tal cultura - debilidades prefiere llamarle éserlan básicamente las siguiente: (a) invasión del erotismo. del psicologismo, eic., bajo el pretrexto de que la sexualidad es una fuente de liberación personal; (b) preeminencia del compromiso político en la producción de la expresión humana, lo cual constituye, de hecho, un evidente signo de impotencia del hombre de hoy; (c) transformación completa del artista en autor que exije reconocimiento como 《creador»; (d) ceguera de la especialización; (e) y, finalmente, la marcada ausencia de la filosofla de la comprensión del mundo y cuyo vaclo se ve inmediata y constantemente invadido por puntos de vista de la ciencia particular?.

En resumen, del diagnostico de Colli sobre la crisis de la modemidad se desprende la clara implicación de que hay que arrancar a la cultura de su servidumbre política. Unicamente desmontando los mecanismos operativos de ese cultura espuria que proclama tales <<verdades〉>, es posible pensar en la adquisición de nuevos valores capaces de vincular al hombre con la grandeza originaria, con la afirmación del verdadero significado de la vida. La anterior empresa no se representa como una tarea sencilla de realizar por dos razones básicas. En primer lugar, porque el llamado a emprenderla es el filosofo en su comprensión clásica presocrática - "de terrible"- y no de la desfiguración moderna -como "cordero"- de un sujeto que se deja al margen de la vida y a quien solamente le queda la ingrata e ignorada tarea de escribir e imprimir sus libros". En segundo lugar, porque los recursos de la polftica para dominar a la cultura son numerosos y poderosos. Además, estos recursos son de naturaleza diversa. Por ejemplo, son de naturaleza material en el caso de la sobreabundancia y disponibilidad de los medios de comunicación. Pero, también, son de nauraleza espiritual, en el caso de la abundancia de enfermedades del intelecto, como ocurre, para citar un caso común, cuando nos negamos a formar juicios propios.

Enseguida se analizará el segundo grupo de criticas de Colli a la modernidad, aglutinadas en torno a la renuncia de la subordinación de la filosofla a la ciencia. Al respecto, lo primero que habrla que recalcar es que si algo marca el espíritu de la modernidad es su pretensión de dominación ilimitada del entomo global, natural, sustentada en una presunta condición de autonomia de la condición humana". Tal "racionalidad instrumental", supuestamente justificada por los éxitos de aplicación empírica y predictiva del conocimiento científico, constituye tal vez la principal responsable de la decadencia del mundo modemo. El hecho fundamental es que para Colli, la ciencia ha dejado de representar un valor por si misma. 
5. Colli nos sehala explícitamente que su concepción de grandeza se encuentra irspirada en la concepción de grandeza contenida en los Upanisad de los videntes vedicos. Es decir, en la sabidurfa milenaria de la filosoffa y la religión hindú. Por lo demás, es una concepción de grandeza que comparte elementos con otras visiones de grandes maestros de la "metapolílica" como son Nietzsche (con la mirada que traspasa la mera representación que llamamos realidad y trata de percibir lo oculto tras la apariencia), Calasso (con su actuar político dentro del tortente pero a la distancia) y Junger (con su concepción del emboscado). Todos ellos, pues, comparten ese Pathos contemplativo deudor de los Vedas que observa a la distancia el dinamismo del mundo moviendose entre el dolor y el tiempo.

6. Esta afirmación nos lleva a la concepción de realidad última manejada por Colli y, en rigor, está tomada del pensamiento griego presoctático. Según Colli. en ente sentido, "el mundo en que vivimos es tan sólo una apariencia, una ilusión, con consistencia de suello". Cf: lbld., p. 52. Para profundizar en esta concepción metafísica clásica debe leerse con sumo cuidado la que quizá es la obre cumbre de Colli Fllosofía de la Expresión.

7. Ibld., pp. 47-48.

8. Dice Colli: "nos circunda y artastra un gran ró el que llamamos vida, naturaleza, historia (humanidad). Esta corriente vertiginosa nos da sentimientos, opiniones y pensamientos, y luego nos lo vuelve a quitar. Aquel que consigue no estar sometido al arrastre, y consigue de vez en cuando acuñar por si solo un pensamiento. equel es un individuo. (...) Tal individuo es, para sus semejantes, un "terrible", como declan los antiguos, aunque los modernos no parecen tener ese miedo, tal vez porque no es muy frocuente que tengan que verselas con un filosofo", $I b i d ., p .50$.

9. También Roberto Calasso nos pone en guardie con todos los supuestos metafisicos, epistemológicos y antropológicos que están atrás de la concepción y el abuso de la razón instumental, expresada en la organización contemporánes de la ciencia y en la pretensión experimental de la historia. Como nos dice Calasso: "La posthistoria está habitada por hombres que creen en las "causas", pero en el "hombre", en la "sociedad". en muchas hipostasis mís, pero está gobernada por un individuo guesón tal vez lambien trascendental para el cual rodo es material, todo permutable, codo utilizable; un perpetuo manipulador que inventa las formas y las arroja, se cante de los materiales más habiuales y busca siempre otros inteditos, excava las selva amnónicas y perfora la cornisa polar para ariadir un sabor, un aroma remoto al cicaón". Cf: Calasso, R. La ruina de Kasch, Barcelona, Anagrama, 1989, p. 248.

10. Colli, G. El libro de ... op. cit., pp. 87-89.

11. Colli nos advierte: "Hoy en dia no podemos decir que la filosofia este en decadencia: la filosofla ya no existe, existe mucho menos que una poesla o una pintura. Y como nunca antes han existido tantos hombres que se hacen llamar filosofos - a juzgar por los congresos de filosofla o las revistas y publicaciones-, se podría pensar que la filosolfa está en un buen momento, pero en realidad casi todos la desprecian y con razón; para conseguir una seriedad se deberfa de renunciar al nombre de filosofia y filosofo, mimetizarse y comenzar de nuevo", Cf: lbid., p. 95.

12. También el viejo Marx apeló a la estructura de la inversión, al encontrar la fuente de los males del capitalismo en la alienación o cosificación de los productos del trabajo que pasaban a autonomizarse y levantarse frente al hombre. su productor. como realidades con existencia y dinamismo independiente de ese su productor. 